\title{
HACIA EL SUJETO FEMENINO EN LA LITERATURA ${ }^{1}$
}

\author{
Ana Isabel Martín Puya \\ (Universidad de Córdoba) \\ anaisabel.martin@uco.es
}

\begin{abstract}
La poesía es un trabajo ideológico perfectamente objetivo, que puede saltarse -y esto es lo grave - las normas de la ideología dominante, incluso cuando están grabadas a fuego [...] en el propio poeta -y no digamos en los lectores-.
\end{abstract} Juan Carlos Rodríguez

La literatura no ha existido siempre; la frase de Juan Carlos Rodríguez (1990 [1974]: 9) se ha convertido para algunos de nosotros en una especie de mantra que con frecuencia nos repetimos para no caer en las garras de las nociones esencialistas de lo literario. En relación con la radical historicidad de la literatura y con la creación burguesa del sujeto (libre), necesario para la existencia de un sistema capitalista (frente al siervo feudal), la aparición de la literatura como medio de producción ideológica (y de legitimación de las nuevas relaciones sociales y claves conceptuales que las sustentan) es posible precisamente a partir de tal liberación del individuo, ahora sujeto autónomo. Como se sabe, el inmovilismo feudal irá cediendo progresivamente su lugar a la movilidad social y al nacimiento de la literatura del «yo», en un periodo de transición y de contradicciones en que debe construirse el nuevo sujeto y su identidad. ${ }^{2}$ Y la literatura es medio esencial para esa producción ideológica nueva. La noción de «mérito» vinculada al hombre como «hijo de sus obras» se impondrá frente a la jerarquía (y el determinismo) del linaje y la sangre. Y, aunque el territorio de la escritura (en su relación con el poder —en tanto que conceptualiza y legitima lo establecido, pero también como medio subversivo y transgresor-) veda el acceso a la mujer, no son pocas las que se abren paso (y abren camino) empleando mecanismos propios de la mentalidad imperante, pero provocando fisuras, modelizando la transgresión y subversión de los valores y la imagen de lo femenino: construyendo, produciendo el sujeto femenino - en los límites, o al margen, del espacio permitido en la ideología dominante- .

\section{CONDICIONANTES DE LA ESCRITURA FEMENINA}

Si decíamos que la noción de sujeto emerge como necesaria para el establecimiento de la ideología burguesa (para posibilitar/legitimar sus nuevas relaciones sociales y como sustento conceptual), el nacimiento del estado moderno se sostendrá asimismo sobre la base de la dicotomía privado/público (que funciona también en el interior de la propia categoría sujeto): lo público será lo perteneciente al ámbito político, donde se «establece» el interés o bien común, lo institucional y lo normativo, asociado al poder y en el que se instituyen los dos pilares del estado,

${ }^{1}$ Versiones iniciales de los trabajos de este monográfico fueron presentadas en el Congreso Internacional Sujeto literario en la modernidad temprana, celebrado en la Universidad de Córdoba en enero de 2018, y forma parte de los resultados del Proyecto SILEM (Sujeto e institución literaria en la edad moderna, FFI2014-54367-C2-1-R del Plan Estatal de I+D+i).

${ }^{2}$ El sujeto moderno se construye desde el vacío o hueco que supone la pérdida de las incólumes certezas del mundo feudal: el sentido de un mundo regido por la divinidad, con un orden social estático con las funciones de los estamentos claramente delimitadas y conforme a unas normas estables. 
burocracia y ejército (letras y armas); lo privado será el ámbito familiar, la intimidad, lo personal y afectivo. El primero quedará asociado a lo masculino, y sus funciones (los cargos públicos) solo podrán ser ocupadas por hombres; la mujer quedará relegada al espacio de lo privado y sus características serán las identificadas con este ámbito.

Los parámetros de lo público venían impuestos o se codificaban socialmente; el espacio por definir era el de lo privado, la intimidad, la subjetividad moderna, en cuya producción tenía un papel destacado la literatura (Folger, 2016); no solo en tanto que modelización del sujeto compartido, asimilado e interiorizado por los lectores, sino también como modelización del propio sujeto autorial (el self-fashioning). En la temprana modernidad, como recientemente ha indicado Ruiz Pérez (2018: 28),

El peso de la ideología (entendida como el conjunto de principios que rigen una colectividad en el plano filosófico, político, religioso y social) se traslada a la estética y, antes que a ella, a la propia práctica artística, condicionando la posición y el habitus del escritor. Es en la tensión que mantiene con ella, entre el rechazo y la aceptación, donde se forja su identidad autorial y su perfil como creador [...] en la relación con los valores de su momento y de su entorno, condicionando sus prácticas particulares.

Paralelamente a la aparición de la conciencia autorial y la subjetividad moderna, a los mecanismos y prácticas que darán lugar a un emergente campo literario, también las mujeres irán conformando y manifestando (condicionadamente) una conciencia autorial. Aunque con el añadido que suponía su condición de género (con todas las implicaciones que esto conllevaba), la mujer escritora participa de las dinámicas y procesos propios de este estadio de formación de la conciencia autorial, el campo literario y las nuevas prácticas. Ejemplos señeros de las dificultades a que se enfrentaron y de mecanismos adoptados para solventarlos son los casos de autoras como Teresa de Ávila, María de Zayas o sor Juana Inés de la Cruz. Circunstancias, actitudes y obras de estas y otras autoras se abordan en este monográfico.

Las limitaciones de la escritura de las mujeres en la temprana modernidad se inician en la concepción misma de su educación: en el Siglo de Oro, «si el aprendizaje de la lectura [limitado a obras que pudieran cultivar su "vida espiritual"] era defendido por casi todos los tratadistas que se ocuparon de las mujeres, la escritura tenía una consideración más problemática», ya que «no parecía tener ninguna finalidad espiritual y por el contrario abría un campo a la expresión profana». No obstante, «era el condicionante familiar el que más influía sobre la formación de la niña». De manera generalizada, la escritura femenina se mantendrá oculta, moviéndose entre la «comunicación privada y semi-privada»; sin embargo, en los casos en que esa frontera se supere, la escritura femenina será «puesta en entredicho y suprimida». Mientras que la transgresión de la utilidad «espiritual» de la lectura femenina solo afectaba a la lectora concreta, sobrepasar las fronteras impuestas a la escritura «implicaba un grupo de receptores sobre los cuales la mujer ejercía una autoridad, lo que sin duda era mucho más peligroso» (Baranda, 2003-2004: 64-65, 82). Por esto mismo, el género por excelencia de su escritura será el epistolar.

Si su exclusión del espacio literario hará que las escritoras deban justificar su práctica $\mathrm{y}$, especialmente, sus publicaciones - recordemos, por ejemplo, que santa Teresa de Ávila solo tuvo problemas con la Inquisición al hacer pública su Vida (Martínez-San Miguel, 2006: 263)—, también encontrarán un obstáculo para su escritura en el hecho de tener que adoptar códigos y modelos constituidos para la producción masculina (esto se percibe con nitidez en el caso de la temática amorosa); además, deberán superar asimismo el tratamiento literario de la mujer como objeto (no ya por autoría, sino por la caracterización, el tratamiento y la pasividad de los 
personajes femeninos) y su realidad social a través de la que construirse y autolegitimarse como sujetos enunciadores. ${ }^{3}$

\section{EL SUJETO FEMENINO: CONCEPTO Y PRODUCCIÓN}

El sujeto, término directamente relacionado con subjetividad, aquello que parece ser o representa (o se presenta como) lo más íntimo del individuo, se produce y manifiesta (literariamente) públicamente, se modela en el proceso de la escritura ${ }^{4}$ como (o para la) presentación pública del «yo», en directa vinculación con la noción de selffashioning. El sujeto existe en tanto que se hace visible (como comportamientos, como forma de ver el mundo, etc.; se define, se proyecta) ante los demás. Al tiempo que representa una supuesta esencia, lo que de común existe en el conjunto de seres humanos —o, quizá, al menos inicialmente, en el colectivo «hombres»—, también se construye como modelización de las diferencias individuales, del carácter específico y distintivo.

Tanto los mecanismos y estrategias que emplearán las escritoras para legitimar sus prácticas, introducirse (o en sus intentos por introducirse) en el campo o mercado literarios y autorizar sus obras, como los recursos literarios significativos -y significantes - y la dotación de subjetividad a unos personajes femeninos individualizados (hasta entonces tratados como objeto pasivo -idealizado positiva o negativamente - y objeto de las pasiones del hombre) $)^{5}$ son aspectos que contribuyen a la producción de una subjetividad y un sujeto femeninos. Por tanto, desde la visión (modelada por una ideología - masculina- dominante) de las mujeres autoras, se modela a su vez ese sujeto femenino en construcción, a la par que los elementos del «yo», del sujeto-autor femenino, y esa identidad autorial de la escritora (de cada escritora).

La emergencia de un sujeto y de una subjetividad femeninas en la literatura (espacio de producción de subjetividades y, por tanto, de producción ideológica) solo puede rastrearse a partir de los textos; todo propósito de historizar el surgimiento de esa noción (o su conceptualización efectiva) deberá partir de los escritos literarios. Y dada la complejidad e inabarcabilidad de la cuestión, este monográfico aspira a unas pretensiones más humildes, y se presenta con la confianza de suponer un avance en las reflexiones en torno a la forja (progresiva, abstracta, inmaterial, pero a través de

${ }^{3}$ Como recientemente ha señalado María Martos Pérez (2018: 226), «el sujeto masculino no es solo el único sujeto de cultura, sino que esta se ha construido desde su voz. De ahí que las poetas se afanen en la búsqueda de una expresión de su subjetividad que invierta la dirección del binomio dominante "voz masculina"-“objeto femenino"».

${ }^{4}$ Como recogió Benveniste, «es en y por el lenguaje como el hombre se constituye como sujeto; porque el solo lenguaje funda una realidad, en $s u$ realidad que es el ser, el concepto de ego. La subjetividad [...] es la capacidad del locutor de plantearse como sujeto» (en Sánchez Corral, 1995: 19). Así pues, en lo que nos atañe, el sujeto se constituye en y por el lenguaje escrito y su producción en discurso literario, es decir, en el «proceso de la enunciación» de ese discurso, que es el lugar donde reside la ideología (Sánchez Corral, 1993: 196).

${ }^{5}$ En relación con esta atribución social de espacios, y con la consiguiente exclusión (al menos, conceptual) de la mujer del territorio de la palabra y la escritura públicas, en la literatura de la temprana modernidad queda reducida su presencia, y su tratamiento - hablando siempre en términos generales/instucionales - , al del mero objeto pasivo (como ha sido ejemplificado, especialmente, en el caso de los retratos literarios del Siglo de Oro), y sus características asociadas a las de ese ámbito de lo privado: en ella se cifran las emociones — no la razón—, sus tareas son las domésticas, sus aspiraciones (y únicas opciones) son el matrimonio o el convento. Carece de rasgos definitorios y de personalidad distintiva. Dentro de los propios códigos literarios se inscribe esta visión objetual de la mujer: en el amor cortés, en la tradición petrarquista, en la novela sentimental y en la de caballerías... 
producciones materiales visibles) de ese sujeto femenino dentro de la literatura, atendiendo no solo a la autoconciencia y autorrepresentación de las autoras, sino también a la imagen de la mujer que configuran y que se desprende de sus personajes (de su estructuración, de sus caracteres, de sus acciones), y que, aun siendo lábil y voluble, aun presentándose con sus contradicciones y no siempre en términos que apunten en el mismo sentido, es susceptible de calar y adquirir un reflejo (por más tibio que pudiera resultar) en las figuraciones femeninas y en las obras de autores masculinos. De estos, en cualquier caso, conviene conocer la actitud ante la mujer y la proyección de la femineidad y lo femenino (cuando se da) para poder circunscribir a su momento histórico la literatura de las mujeres. Por último, en este caso, otro factor importante surge en relación con la producción de ese sujeto femenino y su inserción en la tradición, el mercado o incluso el canon: la proyección editorial y la labor de esos otros agentes culturales que juegan un papel relevante en la materialización de la cultura; estos (y los lectores) sancionan, pero también (o precisamente por eso) condicionan la producción literaria de las mujeres.

Aunque somos conscientes de que la búsqueda del sujeto femenino debería sobrepasar los (nada estrechos, por otra parte) límites de las poderosas estrategias de integración y autolegitimación, desde la propia conciencia e identidad autorial, pero también desde la conciencia del estatus marginal que confiere el tratar de establecer en un ámbito construido desde y por reglas masculinas, los trabajos de este monográfico se centran especialmente en estos aspectos, sin duda claves en la producción de la identidad autorial, como elemento central de la búsqueda del sujeto femenino. No obstante, este se encuentra asimismo en las construcciones y estructuraciones literarias no necesariamente, o no siempre, inherentes o directamente dirigidas en este sentido. El reconocimiento de la diferencia impuesta por el hecho de querer articular su discurso literario en un espacio dominado (en todos los sentidos) por agentes y normas masculinos (espacio en el que la incursión [participación] de las mujeres suponía una transgresión y en el que obtener algún reconocimiento o consideración resultaba y resulta, a día de hoy, sumamente más difícil que a los autores masculinos) y el estudio de los mecanismos consiguientemente adoptados por las distintas autoras tanto para legitimar su práctica como para reivindicar su estatuto e identidad autoriales (en la producción del sujeto - de los sujetos - femenino) son base y punto de partida para la profundización en aspectos de análisis y crítica literaria de sus obras atendiendo a la perspectiva del self-fashioning formulado por Greenblatt (1984), de cuya fructífera y enriquecedora aplicación encontramos un excelente ejemplo en la monografía — con sus indiscutibles aciertos y sus arriesgadas lecturas-, dedicada precisamente a sor Juana, que Frederick Luciani publicó en 2004: Literary Self-fashioning in sor Juana Inés de la Cruz.

La construcción del sujeto femenino (y su reconocimiento) no se atiene, por tanto, únicamente a la presencia y defensa de la mujer en las obras de las autoras, sino que en cada caso forman parte de él, asimismo, las manifestaciones, proyecciones y propuestas del «yo», por parte de cada autora, ajenas al (o, si se quiere, no directamente relacionadas con el) propio género.

Los trabajos presentados en este monográfico proporcionan, en su conjunto, una visión abarcadora de los procesos de formación y conceptualización del sujeto femenino, de su percepción histórica como concepto que recoge la representación de la mujer, pero cada uno de ellos nos permite indagar, asimismo, en el sujeto femenino entendido no ya como generalidad - y mucho menos como esencia-, sino como la particularidad de cada una de las autoras (o de sus personajes), como la expresión de una conciencia individual (personal), en tanto que mujeres, pero, sobre todo, en tanto 
que sujetos, por parte de las mujeres (o de los personajes femeninos), para lo que es necesario que se den, que se conciten (o se conjuguen) unas determinadas circunstancias históricas-ideológicas (y en los casos particulares, unas inquietudes intelectuales concretas, unas inclinaciones perseguidas y sustentadas en la obra literaria). ¿Cuáles son esas condiciones? En parte, las que se labran en cada incursión de las escritoras en el universo de lo literario, como transgresión, subversión o relativización de los valores establecidos. Pero, para que esto fuera posible, eran necesarios, en primer lugar, la aparición del sujeto (como concepto, como ideología); la presencia y persistencia de la literatura como elemento de sociabilidad cortesana y, posteriormente, académica (en cuyo espacio puedan inscribirse, aunque en desigual número, las mujeres - algunas mujeres-); la supresión del linaje y la valorización del mérito personal (la noción del ser "hijo de sus obras"); la presencia de un mercado literario que se convertirá en valor en sí mismo (con sus agentes y con la atención y búsqueda de receptores/lectores definidos); la «superación» (cronológica, histórica; no porque sea mejor, sino sencillamente como realidad diferente y definida) de la imitatio clásica como ideal en favor de la originalidad moderna...

Lo que de común puedan tener las autoras, como tales, no pasa de la coincidencia de unas determinadas circunstancias sociales y condicionantes a la hora de querer formar parte de un mundo masculino, la posibilidad de concebirse o querer insertarse en una comunidad de autoras femeninas y la posibilidad asimismo de adoptar modelos comunes (femeninos) o estrategias empleadas por sus antecesoras. Unas condiciones materiales afectadas por condicionamientos ideológicos, sociales y culturales (la norma -implícita o expresa-). La creación de una tradición común, de un canon femenino, situado en los márgenes - pero no al margen ni a expensas - de los postulados vigentes en el campo, la tradición y el mercado literarios; o la creación de una tradición que pretende incorporarse a la canónica. Aspectos materiales (históricos), culturales (que condicionan los anteriores) e identitarios (con otras mujeres-autoras).

La construcción del sujeto literario femenino será entonces su propia manifestación en la obra de las autoras. Su aparición, en mayor o medida, en las diferentes obras y en diferentes periodos históricos y su maduración será la expresión de la conciencia autorial. El estudio del proceso de (re)producción de este sujeto - múltiple y mudable en el tiempo - será posible únicamente atendiendo a la especifidad de las prácticas, estrategias y propuestas literarias de las autoras (en su particularidad / de forma particular), atendiendo a su propia construcción de un «yo» público (y esto, como decíamos, situándolas en relación con sus, también particulares, circunstancias - contexto social, y socioeconómico, cultural, ideológico-).

Porque la literatura es también «un trabajo ideológico perfectamente objetivo [...] que puede saltarse [...] las normas de la ideología dominante» (Rodríguez Gómez, 1999: 61), y a través de ella (adaptándose a, y transgrediendo, la norma establecida) las mujeres han producido su propia subjetividad, su conciencia individual y de género, y han contribuido a la producción de la subjetividad femenina (como noción tanto abstracta como colectiva y con proyecciones materiales en la cotidianeidad), porque su conformación es un proceso histórico y dinámico; «El proceso de maduración de la subjetividad femenina es una gradual toma de conciencia de la propia dignidad» (Flores Ruiz, 2005: 17), conciencia y dignidad a las que, sin duda, las autoras literarias han contribuido a lo largo de los siglos a través de su literatura.

En el presente monográfico se aborda, en definitiva, el sujeto femenino en varias de sus manifestaciones literarias: como sujeto femenino autorial, se producen acercamientos a las estrategias de autolegitimación por parte de las escritoras, atendiendo tanto a los elementos paratextuales como a la construcción de una identidad 
femenina en la estructuración y semantización de sus textos literarios (pudiendo subvertir su lugar en discursos hegemónicos como el de Huarte de San Juan, que estudia René Vijarra). Dichas estrategias son mecanismos destinados no solo a esquivar posibles censuras o a defender la práctica autorial, sino también a la pretensión de introducirse en el mercado, a incorporarse a un campo literario propio de hombres (como parcialmente consigue María de Zayas, cuya producción analiza Emre Özmen), o incluso a procurarse un espacio (por más marginal que pueda terminar siendo) en el Parnaso literario (caso de las autoras del XVIII estudiadas por Helena Establier). Los personajes y sus relaciones manifiestan la subversión de los roles habituales establecidos en la literatura escrita por hombres (como sucede en La lozana andaluza y nos descubre Begoña Souviron). La propia decisión de publicar y la estrategia seguida evidencian, por sí mismos, una fuerte conciencia autorial (se ve en Fernán Caballero, cuyos primeros pasos rastrea Julie Botteron). Pero, como es sabido, la elaboración conceptual de la noción de lo que entendemos (o queremos nominar) como sujeto femenino no tiene como autoras exclusivas a las mujeres, sino que, al estar encuadrada en un contexto (histórico, social y cultural), se conforma asimismo mediante las intervenciones de otros agentes (sea como subversión o silenciamiento de la particularidad, como excepcionalidad). Es por eso que tienen también cabida en este sentido las estrategias editoriales para encauzar publicaciones de autoría femenina, como ocurre en el caso de sor Juana Inés de la Cruz (abordado por Carla Fumagalli), a caballo entre la defensa y legitimación auspiciada por el mecenazgo de la condesa de Paredes y la neutralización de su discurso literario mediante la construcción política y lectura hagiográfica del sujeto sor Juana.

En conjunto, nos muestran estos trabajos que el sujeto (autorial) femenino comparte como característica principal la necesidad de recurrir a estrategias editoriales, discursivas o literarias de legitimación de su propia práctica en ese sentido, en relación con su condición femenina, y la inquietud de abrir a nuevos espacios y sentidos la conceptualización de lo femenino, de resemantizar el sujeto femenino.

\section{OBRAS CITADAS}

Baranda, Nieves (2003-2004), «Mujeres y escritura en el Siglo de Oro: una relación inestable», Litterae, 3-4, pp. 61-83.

Flores Ruiz, Eva María (2005), «Introducción», en Eva María Flores Ruiz (ed.), Almas escritas. Retratos literarios de mujeres andaluzas, 1849-1927, Sevilla, Fundación José Manuel Lara, pp. 7-23.

Folger, Robert (2016), «Hacia la subjetividad moderna», Iberoromania, 84, pp. 161-177.

Greenblatt, Stephen (1984), Renaissance Self-fashioning: from More to Shakespeare, Chicago, University of Chicago.

Luciani, Frederick (2004), Literary Self-fashioning in Sor Juana Inés de la Cruz, Lewisburg, Bucknell University Presses.

Martínez-San Miguel, Yolanda (2006), «Engendrando el sujeto femenino del saber o las estrategias para la construcción de una conciencia epistemológica colonial en sor Juana», Revista de crítica literaria latinoamericana, XX, 40, pp. 259-280.

Martos Pérez, María Dolores (2018), «La voz poética», en Nieves Baranda y Anne J. Cruz (coords.), Las escritoras españolas de la Edad Moderna: historia y guía para la investigación, Madrid, UNED, pp. 225-248.

Rodríguez Gómez, Juan Carlos (1990) [1974], Teoría e historia de la producción ideológica: las primeras literaturas burguesas, Madrid, Akal.

Rodríguez Gómez, Juan Carlos (1999), Dichos y escritos: sobre «La otra sentimentalidad» y otros textos fechados de poética, Madrid, Hiperión. 
Ruiz Pérez, Pedro (2018), «Presentación», Studi Ispanici, 48, pp. 11-31.

Sánchez Corral, Luis (1993), «La violencia como discurso y como relato», en Luz González Ballesteros, Aureliano Sainz Martín, Luis Sánchez Corral y María del Mar Hens Muñoz (eds.), Signos y cultura de la violencia: una investigación en el aula, Córdoba, Servicio de Publicaciones Universidad de Córdoba, pp. 193-253.

Sánchez Corral, Luis (1995), Literatura infantil y lenguaje literario, Barcelona, Paidós. 